\title{
Performance Characteristics Research on Power System of a Four-Valve Compressed Air Engine
}

\author{
Qihui Yu* - Xin Tan - Jianguo Meng - Fei Shang - Xueqing Hao \\ Inner Mongolia University of Science \& Technology, School of Mechanical Engineering, China
}

\begin{abstract}
To alleviate air pollution and eliminate pollutants from internal combustion engines, many researchers have paid more attention to compressed air engines (CAEs). However, the low energy utilization efficiency and low output power of a CAE hinder its development. In this paper, a new kind of CAE, which has four valves is proposed, which reduces the kinetic energy of the flowing air. Through analysis of the CAEs, a mathematical model of the working processes was developed. Using the simulation method, the performance of the new kind of CAE waS obtained. To verify the theoretical model, a prototype of a four-valve of single cylinder piston type CAE was designed, and the experiment was carried out. Parameter influence analysis and optimization were studied to improve the four-valve CAE performance. Results show that, first, the output torque and output power of the four-valves of CAE are higher than of the two-valves of CAE. When the intake pressure is set at 0.6 $\mathrm{MPa}$ and $0.7 \mathrm{MPa}$, and the rotation speed is $450 \mathrm{rpm}$, the output torque of the four-valve of CAE is about 2.7 and 2.2 times that of the twovalve of CAE. The output torque and power differences between the two kinds of CAE ascend sharply with increased rotation speed. Second, the energy efficiency and output power are impacted significantly by the intake valve close angle and exhaust passage diameter. Thirdly, the optimization of the four-valve CAE can significantly enhance the output power compared with two-valve CAE. This research can be referred to in the design of the CAEs.
\end{abstract}

Keywords: four-valve compressed air engine, energy efficiency, output power, optimisation

\begin{abstract}
Highlights
- A design of a four-valve compressed air engine to obtain high output power and efficiency is presented.

- A prototype of a four-valve single cylinder piston type compressed air engine is designed, and experiments are carried out.

- $\quad$ Parameter influence analysis and optimization are studied to improve the four-valve compressed air engine's performance.

- $\quad$ The proposed four-valve compressed air engine can enhance significantly the output power in comparison to two-valve compressed air engine.
\end{abstract}

\section{INTRODUCTION}

One major source of air pollutants is generated from internal combustion engines (ICE) for vehicles [1]. It has been reported that the pollutants produced by ICE are responsible for more than $30 \%$ of air pollutants. To alleviate air pollution and eliminate pollutants from ICE, various alternatives, including battery power driven engines [2], hydrogen fuel cell-based engines [3], liquid nitrogen fuel power driven engines, and hybrid energy driven engines [4] and [5] have been developed. However, looking at these various alternatives, each option has its limitations. For example, battery-operated engines suffer from long charging time, high initial cost, heavy metal pollution, and periodical replacement cost [6]. Distribution and storage are difficult for hydrogen fuel cell driven engines, and building hydrogen generator stations is expensive [7]. Liquid nitrogen vehicles are difficult to use given their high cost. The main power source of hybrid energy driven engines remain fossil fuel, so this kind of engine does not meet zero pollution vehicle requirements [8]. In these situations, the technology of the compressed air engine (CAE) and its utilization in vehicles has become an attractive option, owing to its potential of zero pollution. However, in early tests, the vehicle running on compressed air alone was limited to the storage capacity of the tanks.

To obtain high energy density and store more energy in limited space, the storage pressure reaches several hundred bars. Once the compressed air is released from the tanks, its pressure falls to 30 bar as it passes through the pressure reducer. Even at high pressure, the compressed air carries much less energy than other transportation energy sources. Therefore, the CAE applications will need to overcome limitations in compressed air energy density. To enhance the output power of CAE and improve the energy efficiency, numerous studies have considered the high efficiency and high output power energy conversion system for CAE. Shen et al. built an airpowered motorcycle prototype with a fuzzy logic speed controller; the efficiency is above $70 \%$ [1]. Liu et al. investigated a new rotary intake and exhaust system for a piston type CAE and obtained $2.15 \mathrm{~kW}$ output power at 13 bar [9]. To overcome leakage under high air supply pressure, a new pressure-compensated intake valve was designed by $\mathrm{Yu}$ et al. [10]. Zhang et 
al. studied a single-valve reciprocating expander and pointed out that the pressure loss is mainly caused by the air intake process [11]. Xu et al. designed a heat exchange system of the CAE to prevent ice blocking and improve energy efficiency [12].Yu et al. analysed the influences of some parameters and optimized the energy efficiency and output power with improved NSGA-II [13].

The output power and energy efficiency are significantly influenced by the open and close duration, angle and pressure of the intake and exhaust valves [14].To apply of CAEs as the main power system in automobiles, modifications should be made on a compressed air distribution system of CAE. In this paper, a four-valve CAE is proposed to obtain more energy during the working process. The challenge of this work lies in the energy efficiency. Thus, a multi-objective optimal method is applied to improve energy efficiency. The study aims to obtain a CAE whose energy efficiency is above $20 \%$, and output power is over $5.5 \mathrm{~kW}$.

\section{ENERGY EFFICIENCY OF THE TRADITIONAL CAE}

The energy of compressed air could be converted to mechanical work during the state change process of compressed air. The working process of a single cylinder CAE could be divided into three stages in Fig. 1. The working process has been illustrated in the previous literature.
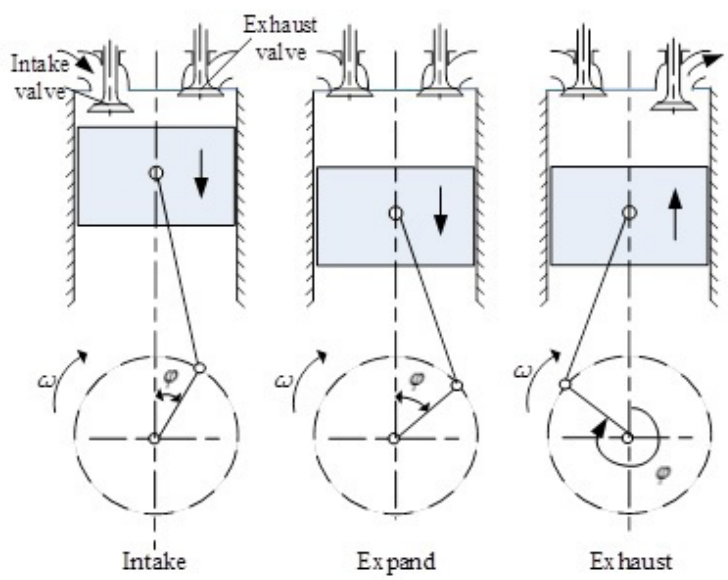

Fig. 1. Working cycle of $C A E$

For CAE, the ideal scenario for performing the maximum level of mechanical work is described as three ideal processes: quasistatic intake processes, isothermal expand process, and quasistatic exhaust process. According to the literature [15], the work done in these processes can be calculated by Eq. (1).

$$
W_{i}=p_{s} V_{s} \ln \frac{p_{s}}{p_{a}},
$$

where $W_{i}$ is the maximum level of mechanical work, $p_{s}$ is the pressure of supply air, $V_{s}$ is the volume of supply air, and $p_{a}$ is the environment pressure.

To determine energy losses and investigate CAE internal energy distributions, the air power is introduced in this paper, which is described by Eq. (2).

$$
P=p_{a} G_{a} \ln \frac{p_{s}}{p_{a}} .
$$

According to the exact definition of air power, the kinetic power of the flowing air, isothermal expansion power and exhaust power are included in the air power calculation. The kinetic energy, expansion, energy and exhaust energy can be expressed with the following equations.

$$
\begin{gathered}
P_{k}=\frac{d}{d t}\left(\frac{1}{2} m v^{2}\right), \\
P_{E}=\frac{\int_{V_{1}}^{V_{2}} p_{1} V_{1}^{\kappa} \frac{d V}{V^{\kappa}}}{d t}, \\
P_{d}=p_{a} G_{a} \ln \frac{p_{d}}{p_{a}} .
\end{gathered}
$$

In the above equations, $P_{k}, P_{E}$ and $P_{d}$ are the kinetic power, expansion power and exhaust power, respectively, $V_{1}$ and $V_{2}$ are the volumes of beginning expansion and finishing expansion respectively, $p_{d}$ is the pressure of exhaust air.

Fig. 2 displays the ratio of $P_{k}$ in intake air power. When the average air velocity is below $100 \mathrm{~m} / \mathrm{s}$, the pressure of air is above $0.3 \mathrm{MPa}$, and kinetic energy accounts for less than $5 \%$ of the available energy. When the average air velocity is above $200 \mathrm{~m} / \mathrm{s}$, kinetic energy accounts for more than $18 \%$ of the available energy. Thus, when the effective cross-sectional area is narrow, and the ratio of the input pressure and output pressure is below the critical pressure ratio, the kinetic energy should be considered.

Fig. 3 shows expansion energy loss in air power. The bigger the polytropic exponent is, the larger the expansion loss is. Therefore, achieving quasiisothermal expansion is an important measure to improve energy efficiency and output power.

It is obvious that the higher the exhaust pressure is, the greater the exhaust energy loss is. Theoretically, energy loss occurs in an irreversible process. Therefore, irreversible processes in CAE systems will reduce the air power. The irreversible process will influence the energy efficiency of a CAE. 


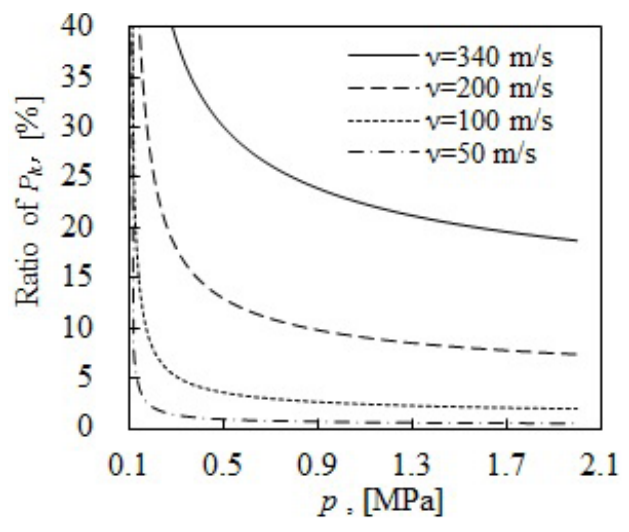

Fig. 2. The ratio of kinetic energy in air power

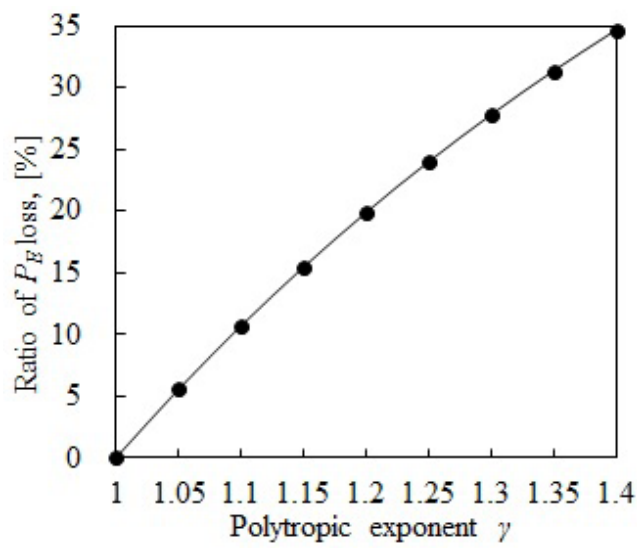

Fig. 3. The ratio of expansion energy loss in air power

In this paper, the efficiency of a CAE is defined as the ratio of the output shaft energy to the input air power of CAE as follows [16].

\section{THE NEW KIND OF CAE WITH FOUR VALVES}

To have precise, continuous valve timing control and fast response, the flow of air moving into and out of the cylinder is controlled by using a simple cam mechanism. The effective area of intake and the exhaust port is determined by cam lift.

According to the ratio of the pressure of the upstream side $p_{u}$ to the pressure of downstream pressure $p_{d}$, the flow equation for the flow through a restriction can be written as follows [17]:

$$
\frac{d m}{d \varphi}=\frac{A_{e} p_{u} \phi}{\omega \sqrt{\theta_{u}}},
$$

where

$$
\phi=\left\{\begin{array}{ll}
\sqrt{\frac{\kappa}{R}\left(\frac{2}{\kappa+1}\right)^{\frac{\kappa+1}{\kappa-1}}} & \frac{p_{d}}{p_{u}} \leq 0.528 \\
\sqrt{\frac{2 \kappa}{(\kappa-1)} \cdot \frac{1}{R}\left[\left(\frac{p_{d}}{p_{u}}\right)^{\frac{2}{\kappa}}-\left(\frac{p_{d}}{p_{u}}\right)^{\frac{\kappa+1}{\kappa}}\right]} & \frac{p_{d}}{p_{u}}>0.528
\end{array},\right.
$$

where $\omega$ is the rotation speed of the crankshaft.

The air mass flowing into the cylinder is inversely proportional to the rotation speed of the crankshaft. Therefore, the higher the speed of the crankshaft, the lower the output torque. To improve the performance under high speed, increasing the effective area is an effective method.

To increase the effective area, a four-valve CAE is proposed. The schematic drawing of the proposed four-valve mechanical structure is illustrated in Fig. 4. Rotations of a crankshaft of CAE are transmitted to both inlet and exhaust cams by using a timing belt and timing pulleys. The cam lift follows the cam profile when appropriate preload springs are used [18].

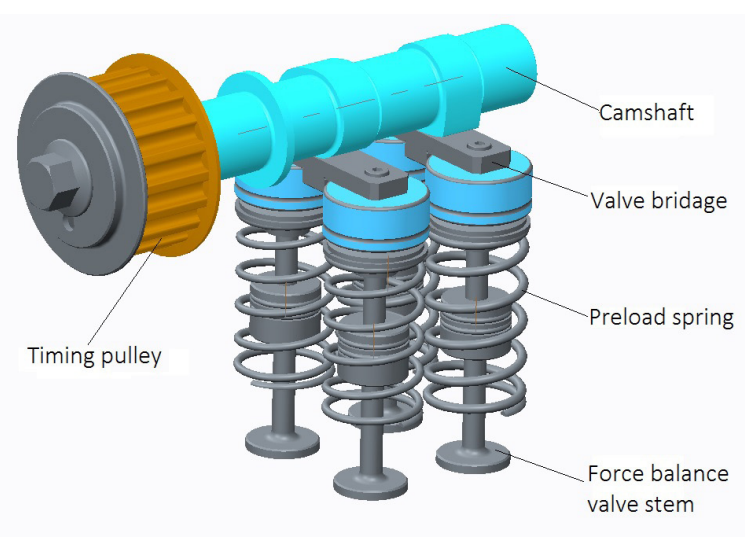

Fig 4. The schematic drawing of the four-valve mechanical structure

The four-valve CAE, which has been applied in the field of traditional internal combustion engines, has a bigger flow effective area and provides more power than the two-valves CAE. Adding more valves improves the mass flow of intake and exhaust compressed air, thereby enhancing output power at high speed. The principle of the four-valve CAE is same as the two-valve CAE, which is introduced in the literature [16]. 


\section{THERMODYNAMIC MODEL AND EXPERIMENT}

To model a pneumatic system, the law of conservation of energy, the equation of continuity and the equation of state of the ideal gas is fundamental [19].

\subsection{The Volume}

The volume of the cylinder is variable due to the movement of the piston. From the piston-crank geometry, the piston displacement, $y$, is expressed by

$$
y=L+r-L \cos \beta-r \cos \varphi,
$$

where

$$
\beta=\sin ^{-1} \frac{r \sin \varphi}{L} .
$$

The volume of the cylinder is given by

$$
V=\frac{\pi D^{2} y}{4} \text {. }
$$

\subsection{The Mass}

According to the law of mass conservation, air mass in the cylinder in one cycle can be given as:

$$
\frac{d m}{d t}=\rho\left(G_{\text {in }}-G_{\text {out }}\right)
$$

where subscript in and out represent the fact that compressed air flows into and out the cylinder.

\subsection{The Pressure}

Pressure changes of the air inside the cylinder can be calculated by deriving the state equation of ideal gases:

$$
\frac{d p}{d t}=\frac{1}{V}\left[R \theta G+m R \frac{d \theta}{d t}-p \frac{d V}{d t}\right] .
$$

\subsection{The Energy}

The temperature differential can be calculated by solving the energy equation. For CAE system, intake process and exhaust process are the open system, expand process is a closed system. For ideal air, accordingly, the energy balance is written by,

$$
\begin{aligned}
C_{v} m \frac{d \theta}{d t} & =h_{e} A_{w}\left(\theta_{a}-\theta\right)+\left(C_{p} \theta_{a}-C_{v} \theta\right) G_{i n} \\
& -R \theta G_{\text {out }}-p \frac{d V}{d t},
\end{aligned}
$$

where $C_{v}$ is the specific heat at constant volume, $C_{p}$ is the specific heat at constant pressure, $h_{e}$ is the heat transfer coefficient which is a constant value, $A_{w}$ is the heat transfer area.

\subsection{The Performance}

The output power and energy efficiency are important evaluate indicators to engine. The output power can be expressed as:

where

$$
\begin{gathered}
P_{e}=\frac{T \times w}{9550}, \\
T=\frac{\int T_{i}}{t},
\end{gathered}
$$

$$
T_{i}=T_{i d}-T_{r}-T_{f}-T_{p}
$$

where $P_{e}$ is the output power, $T_{i}$ is the instantaneous torque, $T_{i d}$ is the indicated torque, $T_{r}$ is the reciprocating torque, and $T_{f}$ is the friction torque. Details of torque calculation are presented in the literature [20].

\subsection{Performance of the Four-Valve CAE}

Compared with the two-valve CAE, the four-valve CAE can achieve a low Mach number, which can reduce the kinetic energy of the flowing air, and the four-valve mechanism can increase the mass flow rate, which can enhance the output power. To obtain the characteristic of four-valve CAE, the initial values of the four-valve CAE mechanism are shown in Table 1. For simplification, the intake valve and exhaust valve have the same structural parameter. MATLAB/ SIMULINK software is used for modelling the simulation. Fig. 5 depicts the output power and energy efficiency characteristics of the multi-valve CAE and the two-valve CAE at different rotational speeds when the supply pressure is equal to $2 \mathrm{MPa}$.

Table 1. Four-valve of CAE specifications

\begin{tabular}{lc}
\hline Type & Value \\
\hline Bore & $85 \mathrm{~mm}$ \\
\hline Stroke & $88 \mathrm{~mm}$ \\
\hline Displacement & $0.5 \mathrm{~L}$ \\
\hline Intake port diameter & $16 \mathrm{~mm}$ \\
\hline Exhaust port diameter & $16 \mathrm{~mm}$ \\
\hline Compression ratio & 10 \\
\hline Minimum diameter of passage & $12 \mathrm{~mm}$ \\
\hline Number of intake valve & 2 \\
\hline Number of exhaust valve & 2 \\
\hline
\end{tabular}

As can be seen from Fig. 5, the curve of the energy efficiency of the four-valve CAE is slightly larger than that of the two-valve $\mathrm{CAE}$, and the output power 
of the four-valve CAE is higher than that of the twovalve CAE by approximately $0.6 \mathrm{~kW}$, which is about 1.1 to 2 times that of the two-valve CAE. Especially when the rotational speed is $600 \mathrm{rpm}$, the highest output power is $3.6 \mathrm{~kW}$.

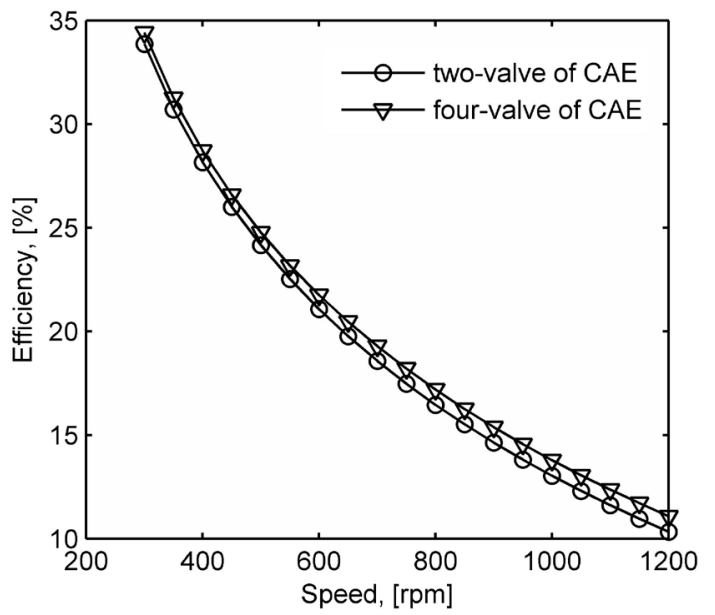

a)

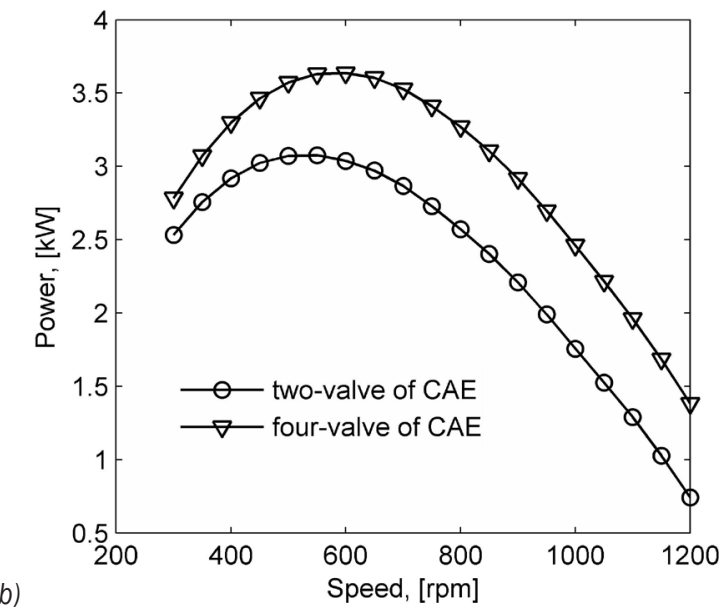

Fig. 5. Efficiency and power of CAE in different rotational speed; a) curves of efficiency, b) curves of power

The output power and energy efficiency characteristics of the four-valve CAE have been studied by setting the rotational speed of the fourvalve CAE at $600 \mathrm{rpm}$, under the supply pressure of the four-valve, at $1 \mathrm{MPa}$ to $3 \mathrm{MPa}$. Fig. 6 illustrates the relationship between the performances and supply pressure of the four-valve CAE.

With an increase in the supply pressure, the output power of the four-valve CAE increases stably. In the first instance, the energy efficiency increases with an increase in the supply pressure; when the supply pressure is larger than $1.8 \mathrm{MPa}$, the energy efficiency slowly drops.
The primary reason is that the indicated pressure inside the cylinder increases with an increase in the supply pressure. The higher the indicated pressure inside the cylinder is, the larger output power is. However, the residual pressure inside the cylinder also increases when the supply pressure is larger than 1.8 $\mathrm{MPa}$ under the exhaust process, which leads to exhaust energy loss.

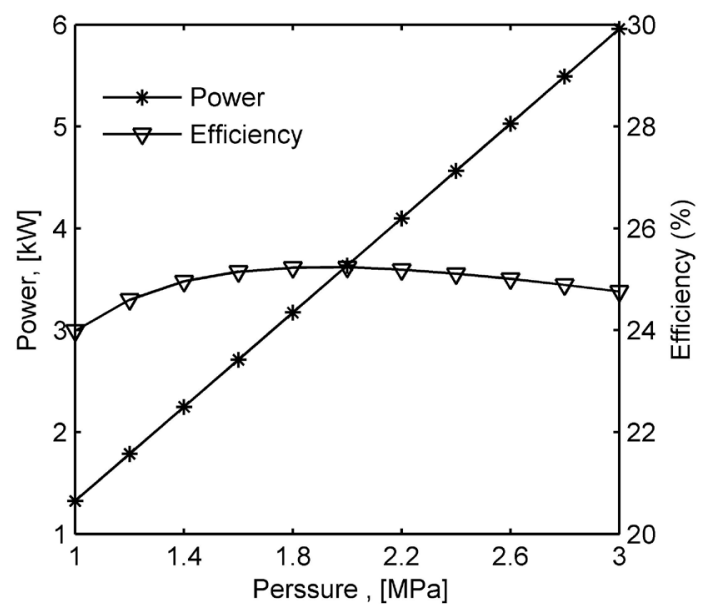

Fig. 6. Efficiency and power of four-valve CAE in different supply pressure

\subsection{Experiment and Analysis}

To verify the above theoretical model, we designed a multi-valve single-cylinder piston type CAE model and prototype, which are shown in Fig. 7. The effective areas of intake and exhaust valves are shown in Fig. 8. Basic parameters are shown in Table 2.

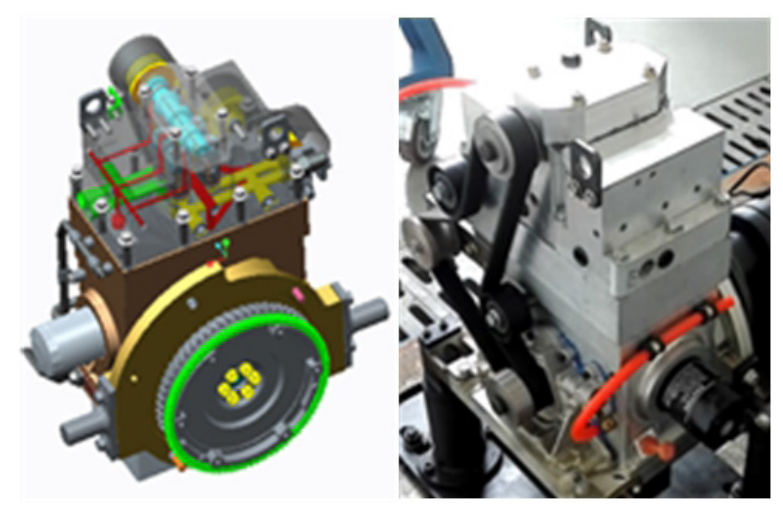

Fig. 7. The model and prototype of multi-valves of CAE

The friction coefficient of the ring assembly is important to calculate friction torque. The correct oil can keep an engine running smoothly. Because the principles of the CAE are different from ICE, it 
is necessary to find the correct lubricating oil to keep the CAE running smoothly and effectively. According to the literature [21], the lower the temperature is, the higher the viscosity is. The working temperature range of CAE is $220 \mathrm{~K}$ to $293 \mathrm{~K}$, so we adopted refrigerator oil as a lubricating oil; its viscosities value are 15 $\mathrm{mm}^{2} / \mathrm{s}$ and $3.1 \mathrm{~mm}^{2} / \mathrm{s}$ when the temperatures are 313 $\mathrm{K}$ and $373 \mathrm{~K}$, respectively.

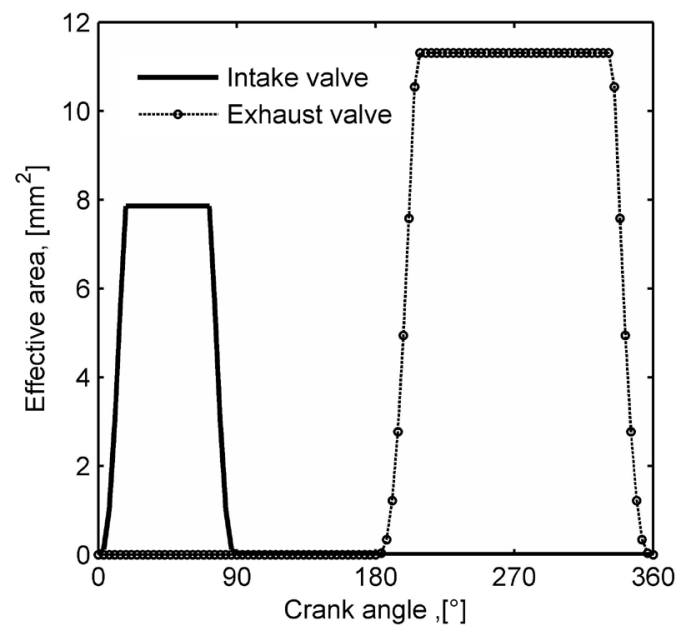

Fig. 8. Effective areas of intake valve and exhaust valve

Table 2. Single cylinder CAE specifications

\begin{tabular}{lc}
\hline Type & Value \\
\hline Displacement & $0.5 \mathrm{~L}$ \\
\hline Number of valves & 4 \\
\hline Opening angle of intake valve & $0^{\circ}$ \\
\hline Closing angle of intake valve & $90^{\circ}$ \\
\hline Maximum cam lift of intake valve & $3.5 \mathrm{~mm}$ \\
\hline Opening angle of exhaust valve & $180^{\circ}$ \\
\hline Closing angle of exhaust valve & $360^{\circ}$ \\
\hline Maximum cam lift of exhaust valve & $5.72 \mathrm{~mm}$ \\
\hline Intake port diameter & $22 \mathrm{~mm}$ \\
\hline Exhaust port diameter & $22 \mathrm{~mm}$ \\
\hline Minimum diameter of passage & $14 \mathrm{~mm}$ \\
\hline
\end{tabular}

To compare performance, the output power and torque of two-valves of $\mathrm{CAE}$ and multi-valves of CAE, the experiment is carried out under same working conditions. The experimental apparatus and the procedure have been introduced in the literature [10]. The intake pressure is set at $0.6 \mathrm{MPa}$ and 0.7 $\mathrm{MPa}$. Experiments of the output torque and output power of the two kinds of CAEs were done, and the results are shown in Fig. 9.

Fig. 9a illustrates the relationship between the output torque and the rotation speed of the two kinds of CAEs. As can be seen, the curves of the output torque of the two kinds of CAEs decline sharply with the rotational speed. Moreover, the output torque of the four-valve of CAE is much higher than that of the two-valve of CAE in the same intake pressure and rotational speed. When the intake pressure is set at 0.6 $\mathrm{MPa}$, and the rotational speed is $450 \mathrm{rpm}$, the output torque of the four-valve $\mathrm{CAE}$ is about 2.7 times that of the two-valve CAE. When the intake pressure is set at $0.7 \mathrm{MPa}$, and the rotational speed is $450 \mathrm{rpm}$, the output torque of the four-valve $\mathrm{CAE}$ is about 2.2 times that of the two-valve CAE. Moreover, the output torque difference of the two kinds of CAE ascends sharply with increasing rotational speed.

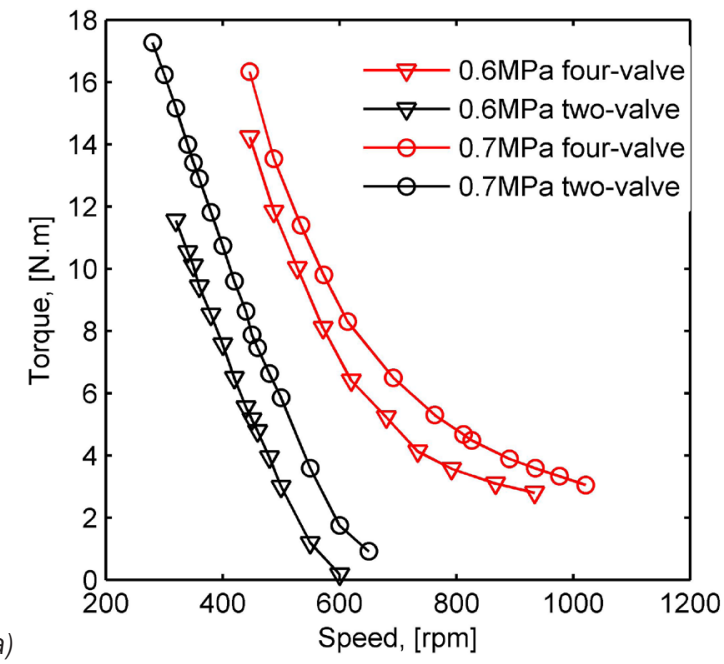

a)

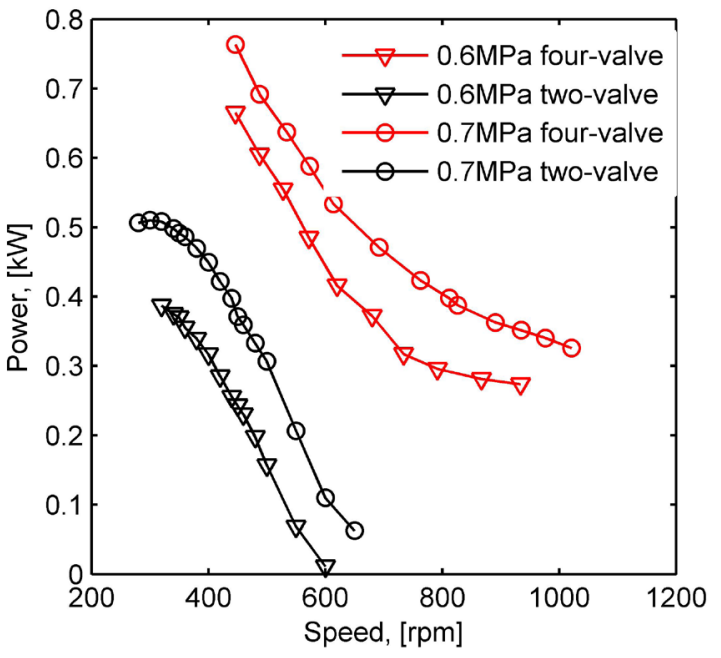

Fig. 9. The output torque and power of the CAEs in different intake pressure; a) torque vs speed and b) power vs speed

Fig. 9b illustrates the relationship between the output power and the rotational speed of the two kinds of CAEs. As can be seen, the curves of the output power of the two kinds of CAEs decline sharply with 
the rotational speed. Moreover, the output power of the four-valve CAE is much higher than that of the two-valve CAE in the same intake pressure and rotational speed. The output power difference of two kinds of CAEs ascends sharply with increased rotational speed.

\section{PARAMETER INFLUENCE ANALYSIS}

In conventional mechanical valve trains, intake and exhaust valves lift are determined by the cam profile. In this paper, the cam profile is described by a five polynomial curve which is given by:

$$
h(a)=C_{0}+C_{p} a^{p}+C_{q} a^{q}+C_{r} a^{r}+C_{s} a^{s},
$$

where

$$
\begin{aligned}
a & =\frac{x}{x_{B}}, \\
C_{0} & =h_{\max },
\end{aligned}
$$

where $x$ is the cam angle, $x_{B}$ is the half wrap angle, superscript $p, q, r, s$ are plural. For simplification, we suppose the following equations [22]:

$$
\left.\begin{array}{c}
p=2 n \\
q=2 n+l \\
r=2 n+2 l \\
s=2 n+4 l
\end{array}\right\},
$$

where, $n, l$ are positive integers.

$C_{p}, C_{q}, C_{r}, C_{s}$ can be calculated by boundary conditions [23] which are functions of $n, l$. In this paper, intake cam profile variable $n_{i}$ and $l_{i}$ are equal to 3 and 6 , respectively, and exhaust cam profile variable $n_{e}$ and $l_{e}$ are equal to 6 and 3 , respectively.

In an actual four-valve CAE system, the compressed air charged from the buffer container flows into the cylinder through the regulator, and the air mass that flows into the cylinder is limited by the effective sectional area of the regulator. The values of the initial parameters are shown in Table 2. The rotation speed is $600 \mathrm{rpm}$, and the supply pressure is $3 \mathrm{MPa}$.

Except the above parameters, according to the thermodynamic model, the output power and energy efficiency are influenced by cylinder clearance distance, $L_{C}$, is the distance between the bottom of the valve and the top of the piston when the piston reaches to the top dead centre, intake cam maximum lift, $I V L$, intake valve close angle, $I V C$, intake valve head diameter, $I H D$, exhaust cam maximum lift, $E V L$, exhaust valve close angle, $E V C$, exhaust passage diameter, $E P D$, exhaust valve head diameter, $E H D$.
The initial values of the above parameters are shown in Table 3.

Table 3. The initial values of the parameters

\begin{tabular}{lcccc}
\hline Parameter & LC & IVL & IVC & IHD \\
\hline Value & $7 \mathrm{~mm}$ & $3.2 \mathrm{~mm}$ & $90^{\circ}$ & $16 \mathrm{~mm}$ \\
\hline Parameter & EVL & EVC & EPD & EHD \\
\hline Value & $5.72 \mathrm{~mm}$ & $360^{\circ}$ & $12 \mathrm{~mm}$ & $16 \mathrm{~mm}$ \\
\hline
\end{tabular}

According to the thermodynamic model above, each parameter can be changed for comparison while all other parameters are kept constant, and the simulation results are varying each parameter, as illustrated in Fig. 10.

It can be seen from Fig. 10 that:

a) The energy efficiency and output power are impacted significantly by the intake valve close angle and exhaust passage diameter. The energy efficiency decreases from $28 \%$ to $20 \%$ with the intake valve close angle increasing from $70^{\circ}$ to $130^{\circ}$. In the first instance, the output power increases with an increase in the intake valve close angle; when the intake valve close angle is larger than $110^{\circ}$, the output power begins to decrease. When the exhaust passage diameter increases from $10 \mathrm{~mm}$ to $16 \mathrm{~mm}$, the energy efficiency increases from $18.2 \%$ to $25 \%$, and the output power increases from $4 \mathrm{~kW}$ to $6.7 \mathrm{~kW}$.

b) The energy efficiency and output power are slightly affected by intake cam maximum lift, exhaust cam maximum lift and exhaust valve close angle.

c) Other parameters have little influence on the output power and energy efficiency.

\section{OPTIMUM PERFORMANCE PARAMETERS}

According to the above analysis, the output power and energy efficiency of the four-valve CAE are influenced by intake valve close angle, exhaust passage diameter, intake cam maximum lift, exhaust cam maximum lift and exhaust valve close angle. Therefore, in this section, the above five parameters will be optimized. Meanwhile, to keep the four-valve CAE running smoothly, the average temperature inside the cylinder is used as another objective function.

The coupling between parameters has no explicit expressions, according to the literature [15]. The independent optimal of individual parameters shows that the output power, energy efficiency, and temperature of a four-valve CAE cannot achieve 

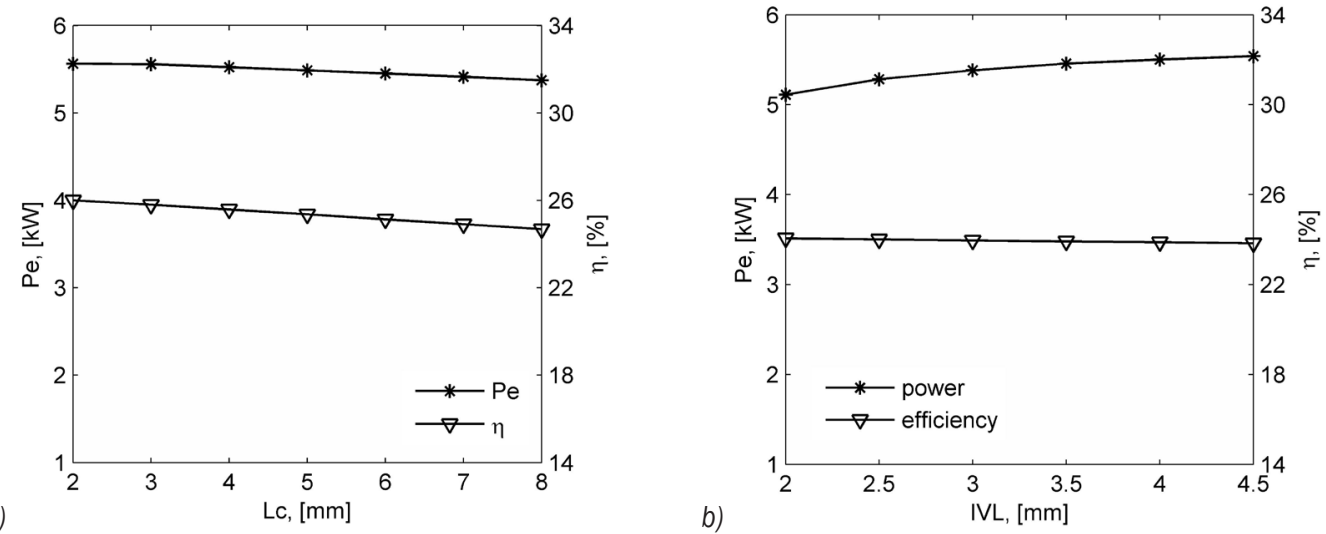

a)

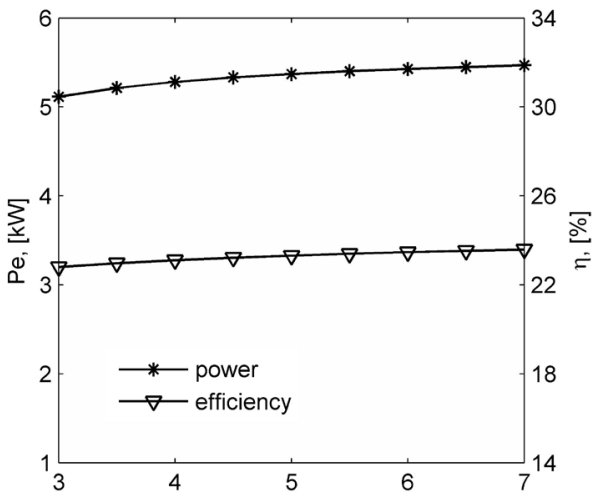

c)

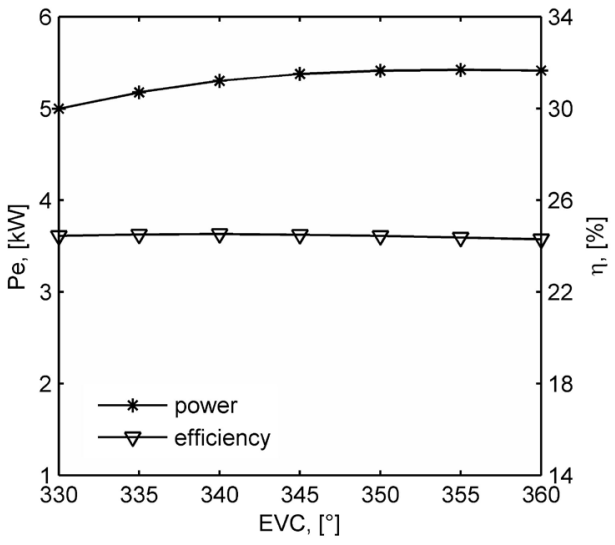

e)

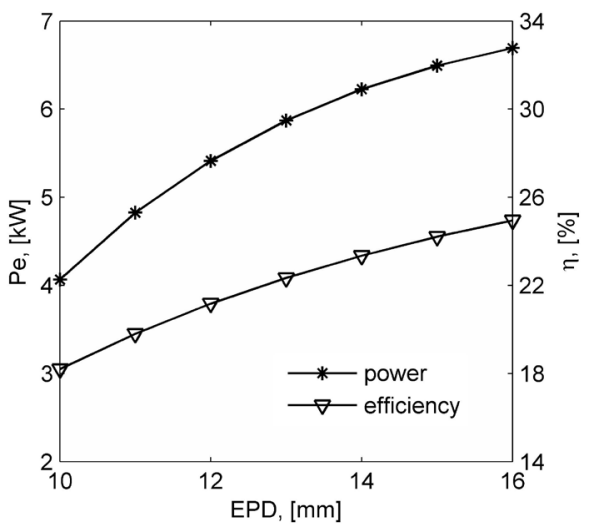

b)
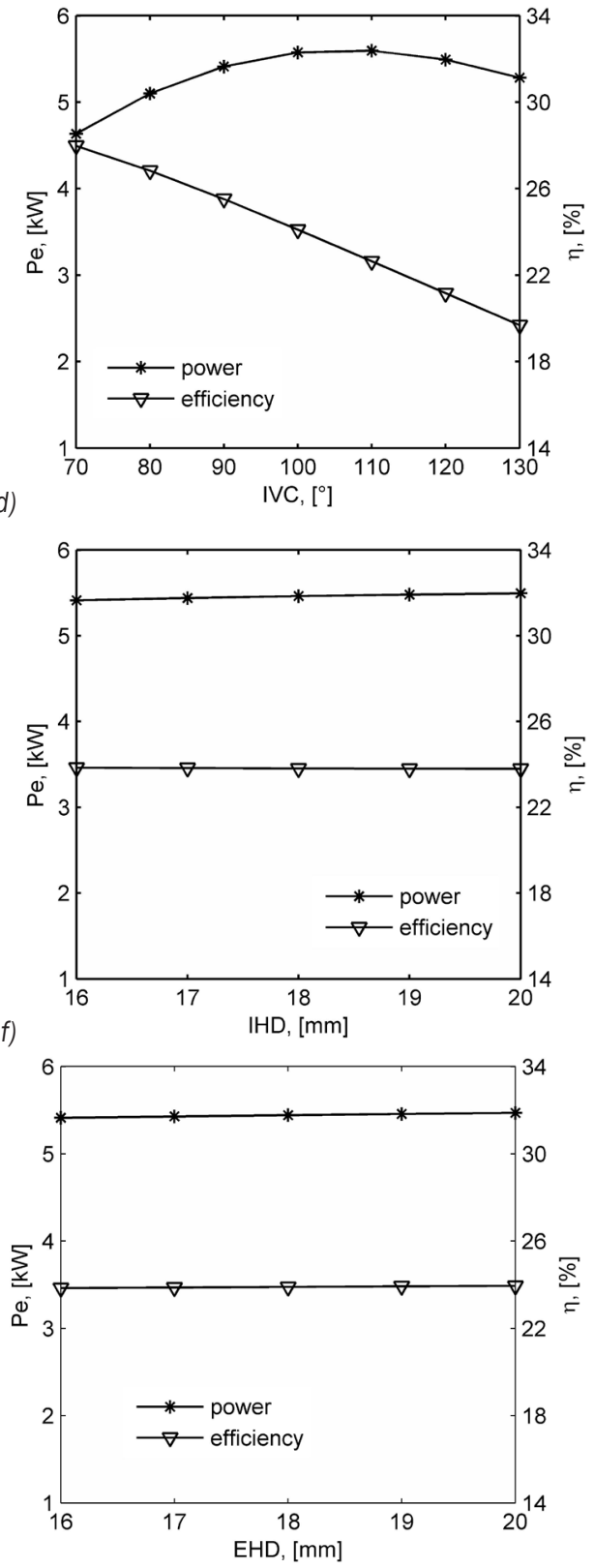

Fig. 10. Influence of parameters on the efficiency and power 
optimum simultaneously. The ranges of parameters are shown in Table 4.

Table 4. Parameters range

\begin{tabular}{lc}
\hline Parameters & Range \\
\hline Intake cam maximum lift (IVL) & $2 \mathrm{~mm}$ to $4 \mathrm{~mm}$ \\
\hline Exhaust cam maximum lift (EVL) & $4 \mathrm{~mm}$ to $7 \mathrm{~mm}$ \\
\hline Intake valve close angle (IVC) & $60^{\circ}$ to $120^{\circ}$ \\
\hline Exhaust valve close angle (EVC) & $330^{\circ}$ to $360^{\circ}$ \\
\hline Exhaust passage diameter (EPD) & $9 \mathrm{~mm}$ to $12 \mathrm{~mm}$ \\
\hline
\end{tabular}

Constraint functions such as the maximum acceleration of the valve train components and the minimum curvature radius are considered in the optimization procedure.

In this paper, an orthogonal design [24] and [25] was used to obtain representative combinations of parameters. The optimal parameter combination for the expected indicators was obtained using grey relation analysis [26] and [27]. A part of the orthogonal array is formed by the parameters in Table 5 .

Table 5. The orthogonal array of the four-valve CAE's parameters (partial)

\begin{tabular}{cccccc}
\hline No. & IVL $[\mathrm{mm}]$ & EVL $[\mathrm{mm}]$ & IVC $\left[^{\circ}\right]$ & EVC $\left[^{\circ}\right]$ & EPD [mm] \\
\hline 1 & 2 & 4 & 60 & 330 & 9 \\
\hline 2 & 2 & 4.75 & 75 & 337.5 & 9.75 \\
\hline 3 & 2 & 5.5 & 90 & 345 & 10.5 \\
\hline 4 & 2 & 6.25 & 105 & 352.5 & 11.25 \\
\hline 5 & 2 & 7 & 120 & 360 & 12 \\
\hline 6 & 2.5 & 4 & 75 & 345 & 11.25 \\
\hline 7 & 2.5 & 4.75 & 90 & 352.5 & 12 \\
\hline 8 & 2.5 & 5.5 & 105 & 360 & 9 \\
\hline 9 & 2.5 & 6.25 & 120 & 330 & 9.75 \\
\hline 10 & 2.5 & 7 & 60 & 337.5 & 10.5 \\
\hline
\end{tabular}

Details of the optimization procedure are presented in [10]. Through simulating calculations with the virtual prototype, the output power, energy efficiency and temperature are shown in Table 6, and the corresponding combination of parameters is shown in Table 7.

Table 6. Optimal performance indicators

\begin{tabular}{lccc}
\hline & Pe $[\mathrm{kW}]$ & $\eta[\%]$ & $\theta[\mathrm{K}]$ \\
\hline range & 4 to 6 & 20 to 40 & 210 to 250 \\
\hline value & 5.95 & 23.1 & 249.9 \\
\hline
\end{tabular}

Table 7. Optimal combination of the parameters

\begin{tabular}{cccccc}
\hline Parameter & IVL $[\mathrm{mm}]$ & $\mathrm{EVL}[\mathrm{mm}]$ & IVC $^{\circ}{ }^{\circ}$ & EVC $\left[{ }^{\circ}\right]$ & EPD [mm] \\
\hline Value & 3.5 & 4 & 105 & 337.5 & 12 \\
\hline
\end{tabular}

\section{CONCLUSIONS}

In this paper, energy loss during the working process was obtained by using air power. To improve output power and energy efficiency, a four-valve CAE was introduced. The prototype was designed to experiment and to compare the performance of the output power and torque of two-valve CAE and fourvalve CAE; the experiment was carried out under same working conditions. The eight factors related to the performance of the multi-valves were discussed, and some key parameters were optimized by using orthogonal design and grey relation analysis. The conclusions are summarized as follows:

1. The output torque and output power of the fourvalve CAE are higher than of the two-valve CAE. When the intake pressure is set at $0.6 \mathrm{MPa}$, and the rotation speed is $450 \mathrm{rpm}$, the output torque of the four-valve CAE is about 2.7 times that of the two-valve CAE. When the intake pressure is set at $0.7 \mathrm{MPa}$, and the rotation speed is $450 \mathrm{rpm}$, the output torque of the four-valves of CAE is about 2.2 times that of the two-valve CAE. Moreover, the output torque and power differences of the two kinds of CAE ascend sharply with increasing rotational speed.

2. The energy efficiency and output power are impacted significantly by the intake valve close angle and exhaust passage diameter. When the intake valve close angle increases from $70^{\circ}$ to $130^{\circ}$, the energy efficiency decreases from 28 $\%$ to $20 \%$. Moreover, in the first instance, the output power increases with an increase in the intake valve close angle; when the intake valve close angle is larger than $110^{\circ}$, the output power begins to decrease.

3. When the inlet pressure is $3 \mathrm{MPa}$, the rotational speed is $600 \mathrm{rpm}$, intake valve lift is $3.5 \mathrm{~mm}$, exhaust valve lift is $4 \mathrm{~mm}$, intake valve close angle is $105^{\circ}$, exhaust valve close angle is 337.5 and exhaust passage diameter is $12 \mathrm{~mm}$, optimal output power equals $5.95 \mathrm{~kW}$, the working efficiency equals $23.1 \%$, and the average temperature inside cylinder equals $249.9 \mathrm{~K}$.

The optimization of the multi-valves CAE can significantly enhance the output power compared with a two-valve CAE. Moreover, the air power efficiency of the four-valve CAE is slightly higher than that of the two-valve CAE. 


\section{ACKNOWLEDGMENTS}

The research work presented in this paper is financially supported by the science and technology innovation Financial Grant (2017CXYD-2) from the Finance Department of Inner Mongolia, Grant 61765012 of the National Natural Science Foundation of China, and Grant NJZZ18139 of the project of science foundation of the educational department of Inner Mongolia.

\section{NOMENCLATURE}

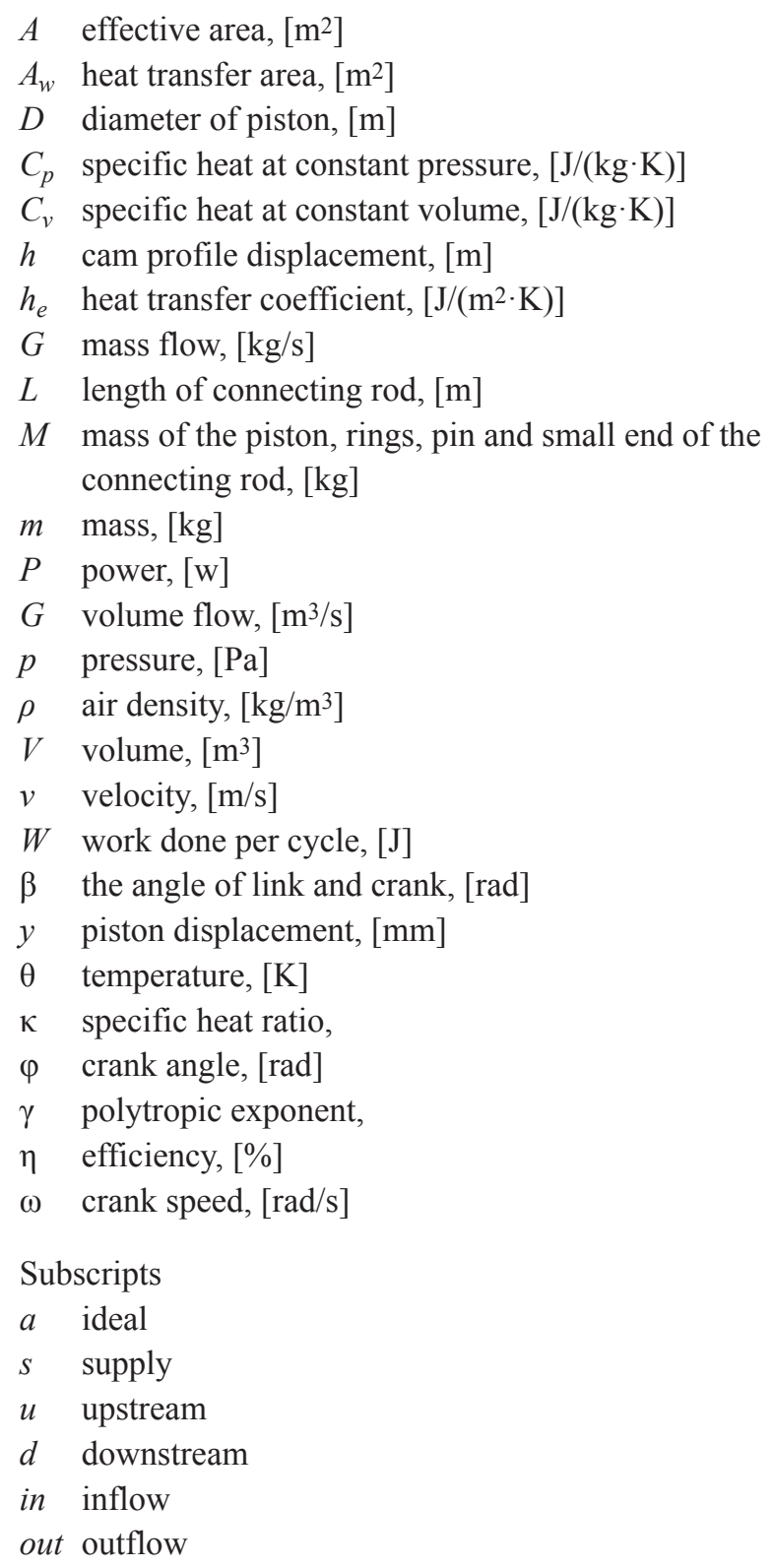

\section{REFERENCES}

[1] Shen, Y.-T., Hwang, Y.-R. (2009). Design and implementation of air-powered motorcycles. Applied Energy, vol 86, no. 7-8, p. 1105-1110, Dol:10.1016/J.apenergy.2008.06.008.

[2] Tesar, D. (2015). Open architecture vehicles of the future. Mechanism and Machine Theory, vol. 89, p. 107-127, DOI:10.1016/j.mechmachtheory.2014.11.007.

[3] Hwang, H.T., Varma, A. (2014). Hydrogen storage for fuel cell vehicles. Current Opinion in Chemical Engineering, vol. 5, p. 42-48, D0I:10.1016/j.coche.2014.04.004.

[4] Huang, K.D., Tzeng, S.-C. (2005). Development of a hybrid pneumatic-power vehicle. Applied Energy, vol. 80, no. 1, p. 4759, D0l:10.1016/j.apenergy.2004.02.006.

[5] Huang, K.D., Tzeng, S.-C., Ma, W.-P., Chang, W.-C. (2005). Hybrid pneumatic-power system which recycles exhaust gas of an internal-combustion engine. Applied Energy, vol. 82, no. 2, p. 117-132, D0l:10.1016/J.apenergy.2004.10.006.

[6] Chan, C.C. (2007). The state of the art of electric, hybrid, and fuel cell vehicles. Proceedings of the IEEE, vol. 95, no. 4, p. 704-718, D0I:10.1109/JPROC.2007.892489.

[7] Offer, G.J., Howey, D., Contestable, M., Clague, R., Brandon, N.P. (2010). Comparative analysis of battery electric, hydrogen fuel cell and hybrid vehicles in a future sustainable road transport system. Energy Policy, vol. 38, no. 1, p. 24-29, DOl:10.1016/j.enpol.2009.08.040.

[8] Singh, B.R., Singh, 0. (2008). Development of a vanedtype novel air turbine. Proceedings of the Institution of Mechanical Engineers, Part C: Journal of Mechanical Engineering Science, vol. 222, no. 12, p. 2419-2426, DOI:10.1243/09544062JMES993.

[9] Liu, C.-M., You, J.-J.,, Sung, C.-K., Huang, C.-Y. (2015). Modified intake and exhaust system for piston-type compressed air engines. Energy, vol. 90, part 1, p. 516-524, D0l:10.1016/j. energy.2015.07.085.

[10] Yu, Q., Cai M., Shi, Y., Xu, Q. (2015). Optimization study on a single-cylinder compressed air engine. Chinese Journal of Mechanical Engineering, vol. 28, no. 6, p. 1285-1292, D0l:10.3901/CJME.2015.0520.072.

[11] Zhang, X., Xu, Y., Jian Xu, J, Xue, H., Chen, H. (2016). Study of a single-valve reciprocating expander. Journal of Energy Institute, vol. 39, no. 3, p. 400-413, D0l:10.1016/j. joei.2015.02.013.

[12] Xu, Q., Cai, M., Shi, Y. (2014). Dynamic heat transfer model for temperature drop analysis and heat exchange system design of the air-powered engine system. Energy, vol. 68, p. 877-885, D0l:10.1016/j.energy. 2014.02.102.

[13] Yu, Q., Cai, M., Shi, Y., Fan, Z. (2014). Optimization of the energy efficiency of a piston compressed air engine. Strojniški vestnik - Journal of Mechanical Engineering, vol. 60, no. 6, p. 395-406, D0l:10.5545/sv-jme.2013.1383.

[14] Xu Q., Shi Y., Yu, Q., Cai, M. (2014). Virtual prototype modeling and performance analysis of the air-powered engine. Proceedings of the Institution of Mechanical Engineers, Part C: Journal of Mechanical Engineering Science, vol. 228, no. 14, p. 2642-2651, DOI:10.1177/0954406214520818.

[15] Cai, M., Kawashima, K., Kagawa, T. (2006). Power Assessment of flowing compressed air. Transactions of the ASME, 
Journal of Fluids Engineering, vol. 128, no. 2, p. 402-405, DOI:10.1115/1.2170129.

[16] Yu, Q., Cai, M., Shi, Y., Yuan, C. (2015). Dimensionless study on efficiency and speed characteristic of a compressed air engine. Journal of Energy Resources Technology, vol. 134, no. 4, p. 044501, D0l:10.1115/1.4029867.

[17] Pipan, M., Herakovič, N. (2016). Volume flow characterization of PWM-controlled fast-switching pneumatic valves. Strojniški vestnik-Journal of Mechanical Engineering, vol. 62, no. 9, p. 543-550, D0I:10.5545/sv-jme.2016.3531.

[18] Nagaya, K. (1989). Nonlinear transient response of a high speed driven value system and stresses in valve spring for internal combustion engines. Transaction of ASME, Journal of Vibration, Acoustics, Stress, and Reliability in Design, vol. 111, no. 3, p. 264-271, Dol:10.1115/1.3269851.

[19] Shi, Y., Cai, M. (2011). Working characteristics of two kinds of air-driven boosters. Energy Conversion and Management, vol. 52, no. 12, p. 3399-3407, D0l:10.1016/j. enconman.2011.07.008.

[20] Zweiri, Y.H., Whidborne, J.F., Seneviratne, L.D. (1999). Dynamic simulation of a single-cylinder diesel engine including dynamometer modelling and friction. Proceedings of the Institution of Mechanical Engineers, Part D: Journal of Automobile Engineering, vol. 213, no. 4, p. 391-402, DOl:10.1243/0954407991526955.

[21] Seeton, C.J. (2006). Viscosity-temperature correction for liquids. Tribology Letters, vol. 22, no. 1, p. 67-78, D0l:10.1007/ s11249-006-9071-2.
[22] Cui, Y., Song, Y., Dai, Z., Deng, K. (2010). Power oriented cam profile optimization for gasoline engine. Chinese Internal Combustion Engine Engineering, vol. 31, no. 4, p. 21-24. (in Chinese)

[23] Shi, Y., Xiao, J.S., Liu C.X., Cui, D.Z., (2002). Sequential unconstrained minimization technique and augmented Lagrange method for optimal design of engine inlet valve cam. Journal of Wuhan University of Technology, vol. 26, no. 3, p. 77-80. (in Chinese)

[24] Chen, J.L., Au, K.C., Wong, Y.S., Tam, N.F.Y. (2010). Using orthogonal design to determine optimal conditions for biodegradation of phenanthrene in mangrove sediment slurry. Journal of Hazardous Materials, vol. 176, no. 1-3, p. 666-671, D0I:10.1016/j.jhazmat.2009.11.083.

[25] Liao, Y., Lian, Z., Feng, J., Yuan, H., Zhao, R. (2018). Effects of multiple factors on water hammer induced by a large flow directional valve. Strojniški vestnik - Journal of Mechanical Engineering, vol. 64 , no. 5, p. 329-338, D0I:10.5545/svjme.2017.5109.

[26] Xia, X.T., Li, J.H. (2011). Influence of vacuum on friction torque of rolling bearing for space applications based on optimum grey relational space. Journal of Grey Systems, vol. 23, no. 4, p. 327-334.

[27] Wei, G.W. (2010). GRA method for multiple attribute decision making with incomplete weight information in intuitionistic fuzzy setting. Knowledge-Based Systems, vol. 23, no. 3, p. 243-247, DOI:10.1016/j.knosys.2010.01.003. 